Polymer Degradation and Stability

Volume 133, November 2016, Pages 192-200

http://dx.doi.org/10.1016/j.polymdegradstab.2016.08.016

http://www.sciencedirect.com/science/article/pii/S0141391016302543

\title{
MELT STABILIZATION OF POLYETHYLENE WITH DIHYDROMYRICETIN, A
}

\section{NATURAL ANTIOXIDANT}

B. Kirschweng ${ }^{1}$, K. Bencze ${ }^{1}$, M. Sárközi ${ }^{1}$, B. Hégely ${ }^{3,4}$, Gy. Samu ${ }^{3,4}$, J. Hári ${ }^{1}$, D.

Tátraaljai $^{1,2}$, E. Földes ${ }^{1,2}$, M. Kállay ${ }^{3,4}$, B. Pukánszky ${ }^{1,2, *}$

${ }^{1}$ Laboratory of Plastics and Rubber Technology, Department of Physical Chemistry and Materials Science, Budapest University of Technology and Economics, H-1521 Budapest, P.O. Box 91, Hungary

${ }^{2}$ Institute of Materials and Environmental Chemistry, Research Centre for Natural Sciences, Hungarian Academy of Sciences, H-1519 Budapest, P.O. Box 286, Hungary

${ }^{3}$ Spectroscopy Laboratory, Department of Physical Chemistry and Materials Science, Budapest University of Technology and Economics, H-1521 Budapest, P.O. Box 91, Hungary ${ }^{4}$ MTA-BME Lendület Quantum Chemistry Research Group, Department of Physical Chemistry and Materials Science, Budapest University of Technology and Economics, H-1521 Budapest, P.O. Box 91, Hungary

*Corresponding author: Laboratory of Plastics and Rubber Technology, Department of Physical Chemistry and Materials Science, Budapest University of Technology and Economics, H-1521 Budapest, P.O. Box 91, Hungary. Tel: 36-1-463-2015, Fax: 36-1-4633474, E-mail: bpukanszky@ mail.bme.hu 


\section{ABSTRACT}

Experiments have been carried out to compare the stabilization effect of two flavonoid type natural antioxidants, dihydromyricetin (DHM) and quercetin (Q) in polyethylene (PE). Additive concentrations changed between 0 and 500 ppm in several steps and 1000 ppm Sandostab PEPQ phosphorus containing secondary stabilizer was also added to each compound. Both antioxidants are very efficient stabilizers for PE, sufficient melt stability was achieved already at $50 \mathrm{ppm}$ DHM content. At small concentrations dihydromyricetin proved to be more efficient melt stabilizer and it protected the secondary antioxidant better than quercetin. In spite of its better efficiency in melt stabilization, polymers containing DHM had the same residual stability as those prepared with quercetin. Accordingly, the larger efficiency does not result from the larger number of active phenolic hydroxyls in the molecule, but from interactions with the phosphorous secondary stabilizer that is stronger or at least different for DHM than quercetin. In spite that DHM is a white powder, it gave the polymer a brownish color which became deeper with increasing number of extrusions and additive content. Nevertheless, both natural antioxidants can be used efficiently for the stabilization of polymers in applications in which color is of secondary importance.

KEYWORDS: polyethylene, processing stabilization, long chain branching, natural antioxidants, dihydromyricetin, solubility, color

\section{INTRODUCTION}

Polyethylene (PE) is exposed to heat, shear, and oxygen during its processing and use. Adequate stabilization is essential to protect the polymer already during the manufacture of the final product and hinder degradation which usually results in the deterioration of properties. Synthetic antioxidants (AO) are used for stabilization in industrial practice, but 
sometime ago questions emerged regarding the effect of their reaction products on human health [1]. Most of these questions have not been answered satisfactorily yet. As a consequence, more and more attempts are made to find new solutions including the use of natural antioxidants for the stabilization of food [2-4], but also of polymers [5-15]. These compounds usually can be found in vegetables and fruits, are often used as spices and are known to have beneficial effect on the human health.

Several compounds with different chemical structures have been studied as potential stabilizers in polymers and also in polyethylene. Vitamin E, i.e. $\alpha$-tocopherol, is a natural phenolic compound which was shown to be a very efficient antioxidant [5-8] and it is used in practice for the stabilization of hip replacements prepared from ultra-high molecular weight polyethylene (UHMWPE). Attempts were made to use lignin, a natural polyphenol, as stabilizer and it proved to have some antioxidant effect indeed [9-11]. Recently, the stabilization of PE with another natural compound, curcumin, was studied in detail [16] and it was found that its melt stabilizing efficiency is superior to that of the synthetic antioxidant extensively used in industrial practice. The effect of the antioxidant was further enhanced by the addition of a phosphorus containing secondary stabilizer. The study has shown that besides its phenolic - $\mathrm{OH}$ groups, also the linear linkage between the two methoxyphenyl rings participates in stabilization reactions leading to a unique reaction route and increased efficiency.

Quercetin, i.e. [2-(3,4-dihydroxyphenyl)-3,5,7-trihydroxy-4H-chromen-4-one] (Q), is also a natural antioxidant found in fruits, vegetables, leafs and seeds in nature. The compound is a flavonol type flavonoid, which has proven antioxidant, antiviral and anti-inflammatory effect in the human body. It was already used for the stabilization of polyolefins $[17,18]$, and also as a component of active packaging materials [19-22]. Quercetin was added to polyethylene [17], polypropylene [18] and an ethylene vinyl alcohol copolymer 
and it proved to be an efficient stabilizer in all cases. However, quercetin was applied at concentrations of 2000-3000 ppm [17,18] or at even larger quantities in most studies, which raises the question of solubility, efficiency and price.

Although the studies cited above $[17,18]$ proved that quercetin is a very efficient stabilizer in various polymers, several questions remained open. Quercetin is a polar compound with a melting temperature of around $320{ }^{\circ} \mathrm{C}$, thus its solubility in the polymer is limited. Its efficient homogenization is questionable under the usual conditions of polyolefin processing, since the additive does not melt. The concentrations used in previous studies also seemed to be quite large $[17,18]$. In a recent study the melt stabilization effect of quercetin was investigated in a Phillips type polyethylene at much smaller concentrations, in the range of 5 to $1000 \mathrm{ppm}$ [23]. It proved to be very efficient and prevented the formation of long chain branches already at a concentration as small as $50 \mathrm{ppm}$, while its dosage at 250 ppm provided the polymer sufficient residual stability. There were indications that quercetin interacted with the phosphonite secondary stabilizer used and that the mechanism of stabilization might differ from that of hindered phenolic stabilizers routinely used in practice. However, besides the advantages of quercetin, its very high melting temperature, limited solubility in polyethylene and strong yellow color are definite drawbacks for this compound.

The disadvantages mentioned in the previous paragraph might be overcome by the use of another flavonoid type natural antioxidant dihydromyricetin (2R,3R)-3,5,7-trihydroxy-2-(3,4,5-trihydroxyphenyl)-2,3-dihydrochromen-4-one) (DHM). The compound is very similar to quercetin, but it is colorless and has a lower melting temperature. According to our knowledge only two attempts were made to use DHM as a stabilizer in polymers and both were done by the same group [24,25]. Chen et al. added DHM to polyethylene [24] and polypropylene [25] at $2000 \mathrm{ppm}$ and without any secondary antioxidant. According to the authors the additive is more efficient than the commercial stabilizers used as reference. 
They explained the large efficiency with the position and the large number of hydroxyl groups in the molecule, but did not offer any information about melt stability, color, the effect of concentration or stabilization mechanism. As a consequence, the goal of this study was to explore the possibility of using DHM as stabilizer in polyethylene. The effect of the compound was compared to that of quercetin discussed above. Stabilization was studied as a function of composition at much smaller amounts than that used by Chen et al. [24,25]. Special attention was paid to processing stability, solubility and color in the study.

\section{EXPERIMENTAL}

\subsection{Materials}

The polymer used in the experiments was the Tipelin FS 471 grade ethylene/1-hexene copolymer (melt flow rate: $0.3 \mathrm{~g} / 10 \mathrm{~min}$ at $190{ }^{\circ} \mathrm{C}, 2.16 \mathrm{~kg}$; nominal density: $0.947 \mathrm{~g} / \mathrm{cm}^{3}$ ) polymerized by a Phillips catalyst. The additive-free polymer powder was provided by Tisza Chemical Ltd. (TVK), Hungary. Quercetin (Sigma-Aldrich, 95\%) and dihydromyricetin (Y\&L Biotech Co., Ltd., China, 98\%) were added to the polymer in various amounts, at 5, $10,25,50,100,250$ and 500 ppm, to study the effect of additive content on stability. Each compound contained also 1000 ppm Sandostab PEPQ (PEPQ, Clariant) phosphonite secondary stabilizer.

\subsection{Sample preparation}

The polymer and the additives were homogenized in a high speed mixer (Henschel FM/A10) at a rate of $500 \mathrm{rpm}$ for $10 \mathrm{~min}$. The necessary amount of quercetin was dissolved in $200 \mathrm{~mL}$ acetone and the solution was added to the PE powder in the mixer. The resulting powder was dried overnight to remove acetone. DHM was added to the polymer together with PEPQ directly and homogenized in the high speed mixer under the same conditions as 
described above. The dry blend was processed and pelletized in six consecutive extrusion steps at $50 \mathrm{rpm}$ and barrel temperatures of $180,220,260$ and $260{ }^{\circ} \mathrm{C}$ under normal laboratory conditions using a Rheomex S 3/4" type single screw extruder attached to a Haake Rheocord EU 10V driving unit. Samples were taken after each extrusion step. For further studies films of about $100 \mu \mathrm{m}$ thickness were compression molded at $190{ }^{\circ} \mathrm{C}$ and 5 min using a Fontijne SRA 100 machine.

\subsection{Characterization}

The melt flow rate (MFR) of the polymer was determined according to the ASTM D 1238-79 standard at $190{ }^{\circ} \mathrm{C}$ with $2.16 \mathrm{~kg}$ load using a Göttfert MPS-D MFR tester. The residual thermo-oxidative stability of the polymer was characterized by the oxidation induction time (OIT) measured at $200{ }^{\circ} \mathrm{C}$ in oxygen atmosphere with constant, $20 \mathrm{ml} / \mathrm{h}$ flow rate in open aluminum pans using a Perkin Elmer DSC 2 apparatus. The functional groups (methyl, unsaturated and carbonyl) of polyethylene were determined by FTIR spectroscopy on the 100 $\mu \mathrm{m}$ thick compression molded films in transmission mode using a Tensor 27 (Bruker) spectrophotometer. Five parallel measurements were carried out on each sample between 4000 and $400 \mathrm{~cm}^{-1}$ wavelengths at $2 \mathrm{~cm}^{-1}$ resolution by 16 scans. Concentration of methyl, transvinylene and vinyl groups were calculated by absorptions at $1378 \mathrm{~cm}^{-1}, 965 \mathrm{~cm}^{-1}$ and 908 $\mathrm{cm}^{-1}$, respectively. Amount of carbonyl groups were measured by calculating the peak area between 1780 and $1680 \mathrm{~cm}^{-1}$. FTIR spectroscopy was used also for the determination of residual PEPQ content based on the absorption of $\mathrm{P}(\mathrm{III})-\mathrm{O}-\mathrm{C}$ groups at $850 \mathrm{~cm}^{-1}$. The color of the samples was described by the yellowness index (YI) and the optical L* parameter measured on a Hunterlab Colourquest 45/0 apparatus. The UV-VIS spectra of reaction products of quercetin and dihydromyricetin were predicted by Time-Dependent Density Functional Theory (TDDFT) calculations at PBE0 [26]/6-311++G** [27] level. Geometries were optimized 
for these calculations in three steps. First conformations with the lowest energies were identified by molecular mechanics using the Merck molecular force field (MMF94) [28] from 2D structures drawn by using the MarvinSketch (ChemAxon) program, then the selected conformers were optimized by DFT calculations at the PBE0/6-311++G** level with Gaussian09 [29]. The obtained geometries were optimized again after manually orienting hydrogens towards possible intramolecular hydrogen bonds resulting in lower energies. Finally, vibrational frequencies of the resulting conformers were calculated by the same DFT method ensuring their correspondence to local minima.

\section{RESULTS AND DISCUSSION}

The results are presented in several sections. First the structure and physical characteristics of the two natural antioxidants are compared to each other and then their effect on processing stability, residual stability, solubility and color are presented in the respective sections. The possible reason for the differences observed and the mechanism of stabilization are discussed in the last section of the paper. Special attention is paid to color and practical consequences in this final section.

\subsection{Antioxidant characteristics}

We selected DHM as a potential natural antioxidant because it is similar in chemical structure to quercetin, but also differs in several aspects. Both are flavonol type flavonoid compounds with the same basic structure. The most important characteristics of the two antioxidants are listed in Table 1 . The lower melting point can be a clear advantage for DHM, since one can hope that, contrary to quercetin, the stabilizer melts during processing that may lead to its more homogeneous distribution in the polymer. The difference in the color of the two compounds is obvious for the first sight. The strong discoloration of the 
polymer in the presence of quercetin was regarded as a disadvantage in the previous study [23]. We hoped that DHM being a white powder would not have the same effect and we can produce compounds without any strong color.

Table 1 Characteristics of the two natural antioxidants used in the experiments

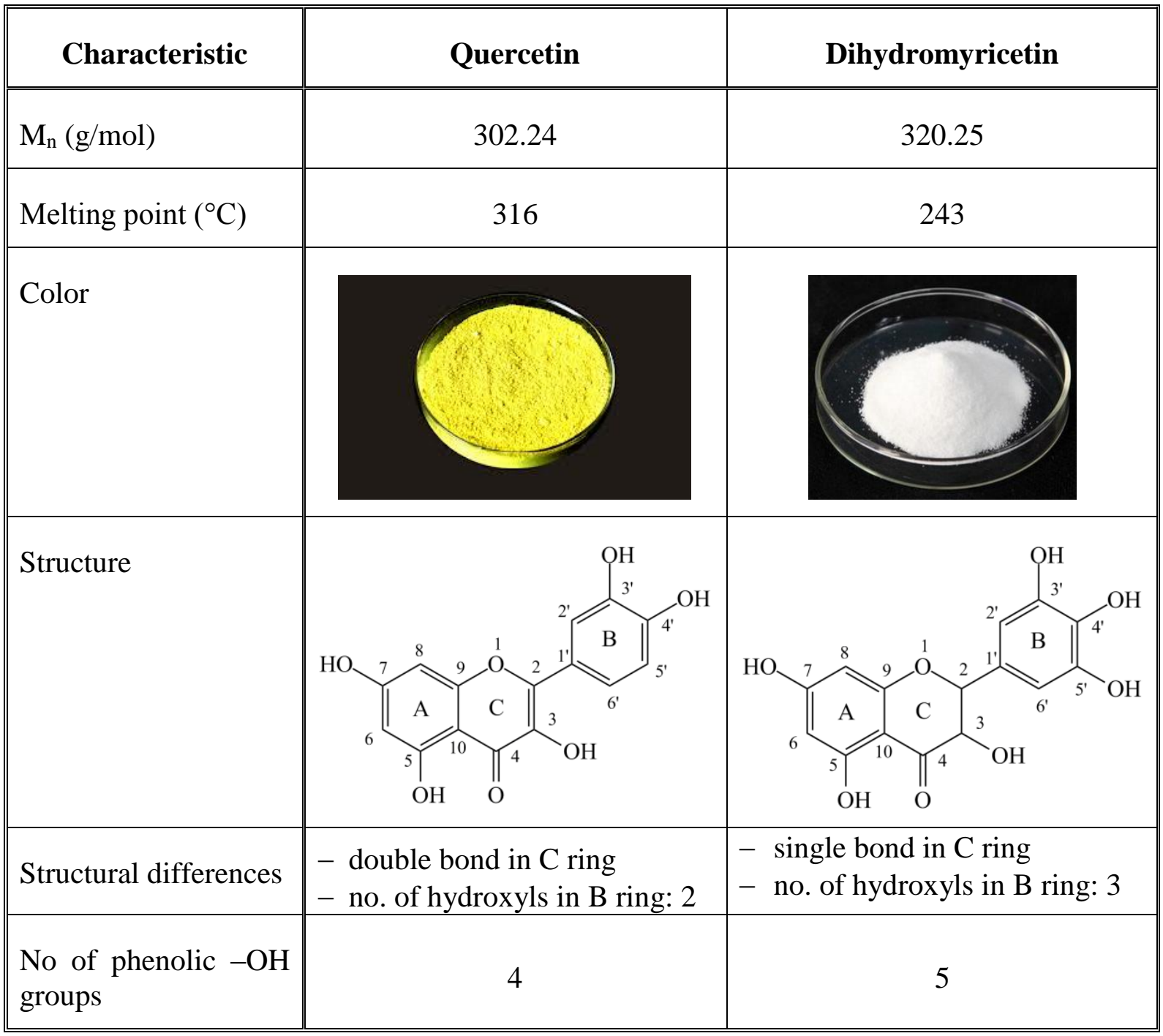

The difference in color is a direct consequence of the chemical structure of the two compounds also shown in Table 1. The strong yellow color of quercetin comes from the conjugation of the double bond in ring $\mathrm{C}$ with the delocalized $\pi$ electrons of ring $\mathrm{B}$. This double bond is missing from DHM. The additional phenolic - $\mathrm{OH}$ group in ring B of DHM is a further difference which might be beneficial for the use of this antioxidant as stabilizer 
in PE. The larger number of phenolic hydroxyl groups would be expected to result in larger efficiency $[24,25]$ further emphasized by the smaller dissociation enthalpy of the $\mathrm{H}$ atom of the pyrogallol structure compared to that of the pyrocatechol moiety [30,31]. All these differences in chemical structure and physical properties promised improved homogeneity, better efficiency and a colorless product, which clearly justified the selection of dihydromyricetin as a potential stabilizer for PE.

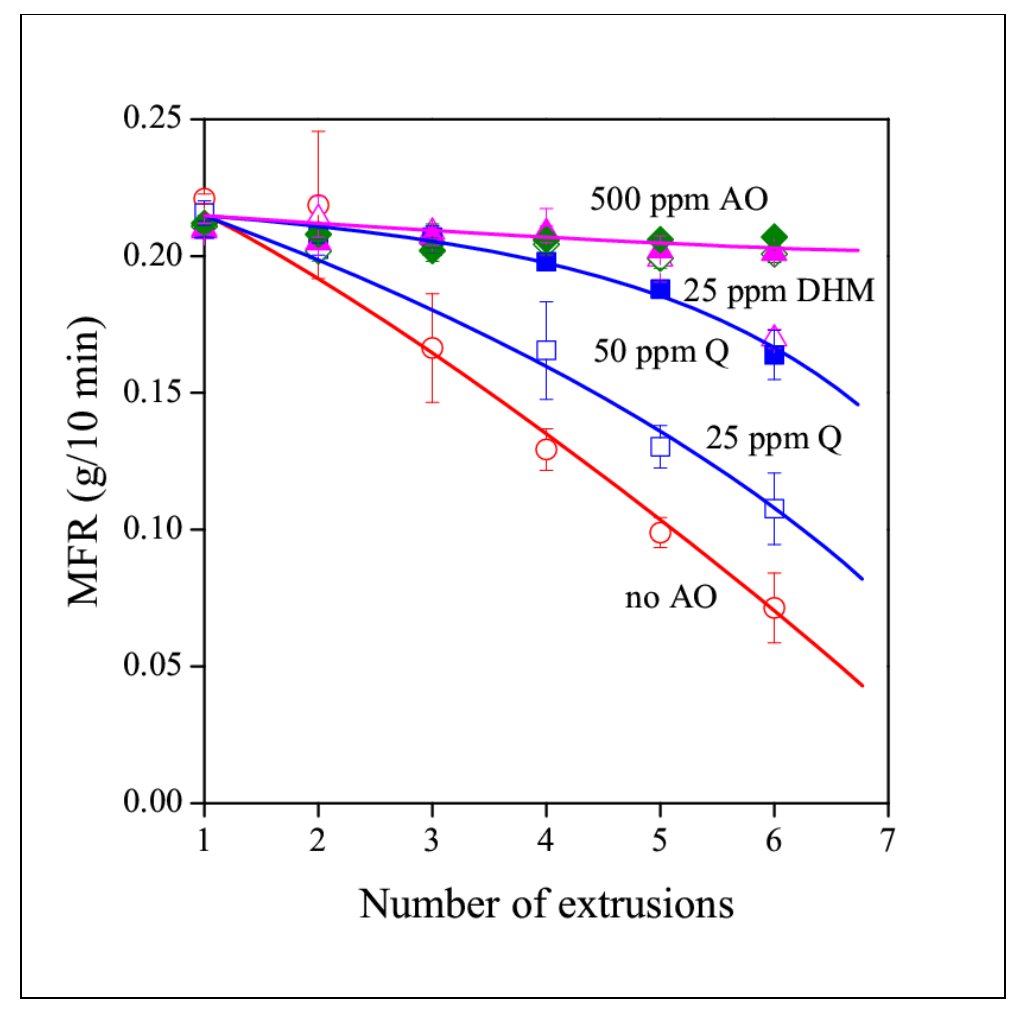

Fig. 1 Effect of additive content and the number of extrusions on the melt stability (MFR) of a Phillips polyethylene. Symbols: $(\bigcirc)$ no primary antioxidant, $(\square) 25,(\triangle)$ 50, $(\diamond) 500$ ppm quercetin, $(\square)$ 25, ( $\mathbf{\Delta})$ 50, $(\diamond) 500$ ppm DHM.

\subsection{Processing stabilization}

The processing of polymers is accompanied by chemical reactions which change their structure. Most polymers, including polyolefins must be protected against these effects 
to maintain their processing and application characteristics. This is especially valid for polyethylenes produced by the Phillips technology, since each molecule contains a vinyl group which reacts readily with oxygen, but also with alkyl radicals. This latter reaction results in the formation of long chain branches (LCB) increasing viscosity and leading to processing problems. As a consequence, changes in the vinyl group content of the polymer is a sensitive indicator of processing stability and they are closely related to the variation, usually increase, of viscosity. Most of these reactions take place in the first processing step and phosphorous secondary stabilizers, PEPQ in this case, protect the polymer very efficiently against such changes.

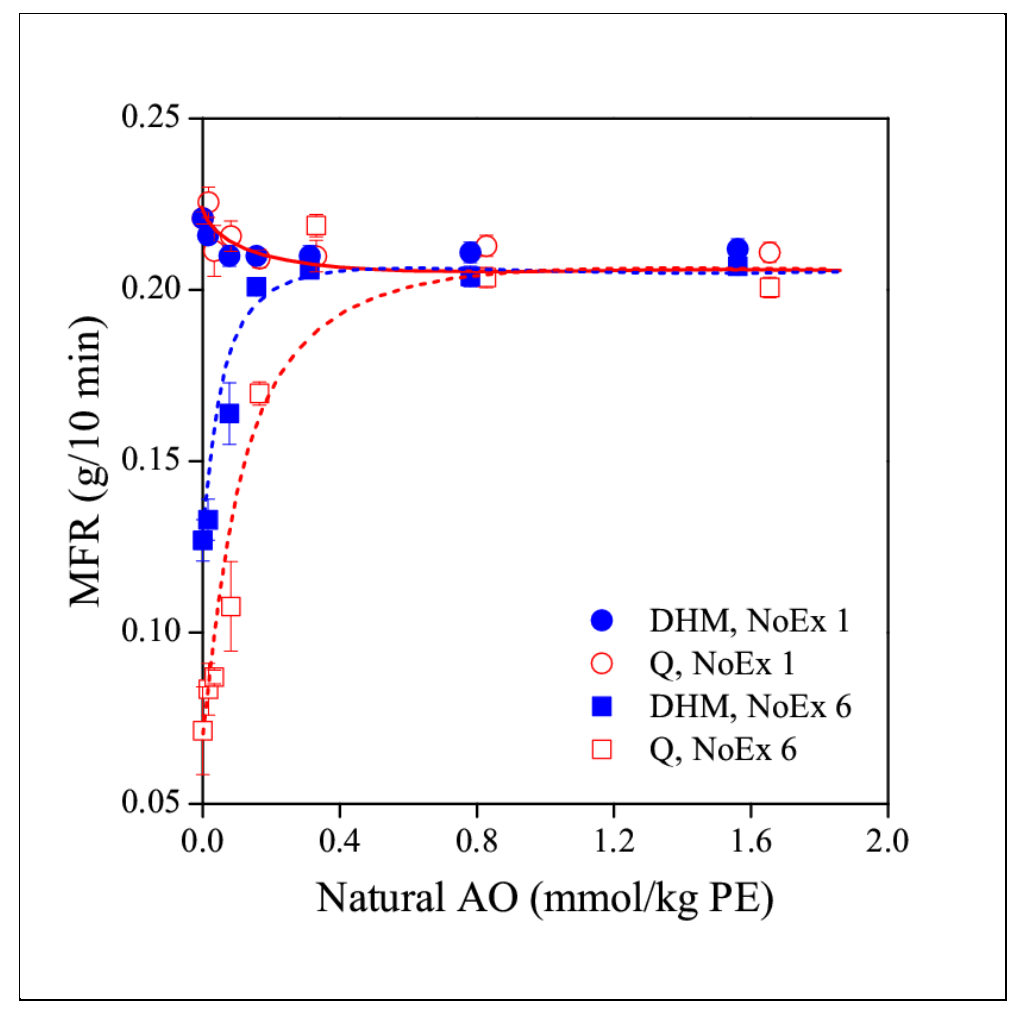

Fig. 2 Dependence of the MFR of polyethylene on stabilizer content at different number of extrusions. Symbols: (○) Q, $1^{\text {st }}$ extrusion, $(\bigcirc)$ DHM, $1^{\text {st }}$ extrusion, $(\square)$ Q, $6^{\text {th }}$ extrusion, (ם) $6^{\text {th }}$ extrusion. 
The MFR of polymers containing either DHM or Q in different amounts is plotted against the number of extrusions in Fig. 1. At zero antioxidant content MFR decreases quite rapidly with increasing number of extrusions. The increase in viscosity is usually associated with the formation of long chain branches [32,33], but cross-linking may also occur eventually. Both antioxidants efficiently hinder these reactions already at very small concentrations. The correlation is shown only for selected antioxidant contents in order to avoid over cramming and confusion in the figure. Already $25 \mathrm{ppm}$ stabilizer is effective and $50 \mathrm{ppm}$ protects the polymer quite efficiently. Above $100 \mathrm{ppm}$ additive content MFR practically does not change. According to the results, DHM seems to be more efficient than quercetin, since the viscosity of the polymer remains constant already at only $50 \mathrm{ppm}$ additive content. Apparently either the larger number of phenolic hydroxyl groups or the smaller dissociation enthalpy of the phenolic hydrogens renders this compound more effective than quercetin.

Melt flow rate is plotted against the amount of stabilizer added to the polymer (Fig. 2) to show the effect of additive content. Since the molecular weight of the two compounds is different (see Table 1), stabilizer content is expressed in mmols. MFR values measured after the $1^{\text {st }}$ and $6^{\text {th }}$ extrusions are plotted to avoid confusion. The effect of the two additives is very similar in the first extrusion, but their dissimilar efficiency is clearly shown after the $6^{\text {th }}$ extrusion at least at small additive contents. Both natural antioxidants protect the polymer very efficiently against degradation at large antioxidant concentrations. It is interesting to note that at very small stabilizer contents MFR decreases, i.e. viscosity increases, after the first extrusion of the polymer that could indicate the formation of long chain branches. This effect is quite surprising considering the considerable efficiency of these stabilizers. However, the phenomenon is the same for both stabilizers and we explained it earlier with the interaction of the primary and the secondary antioxidant (PEPQ) used in this study [23]. The interaction was confirmed by DSC measurements as well [23], but needs further attention 
in the future.

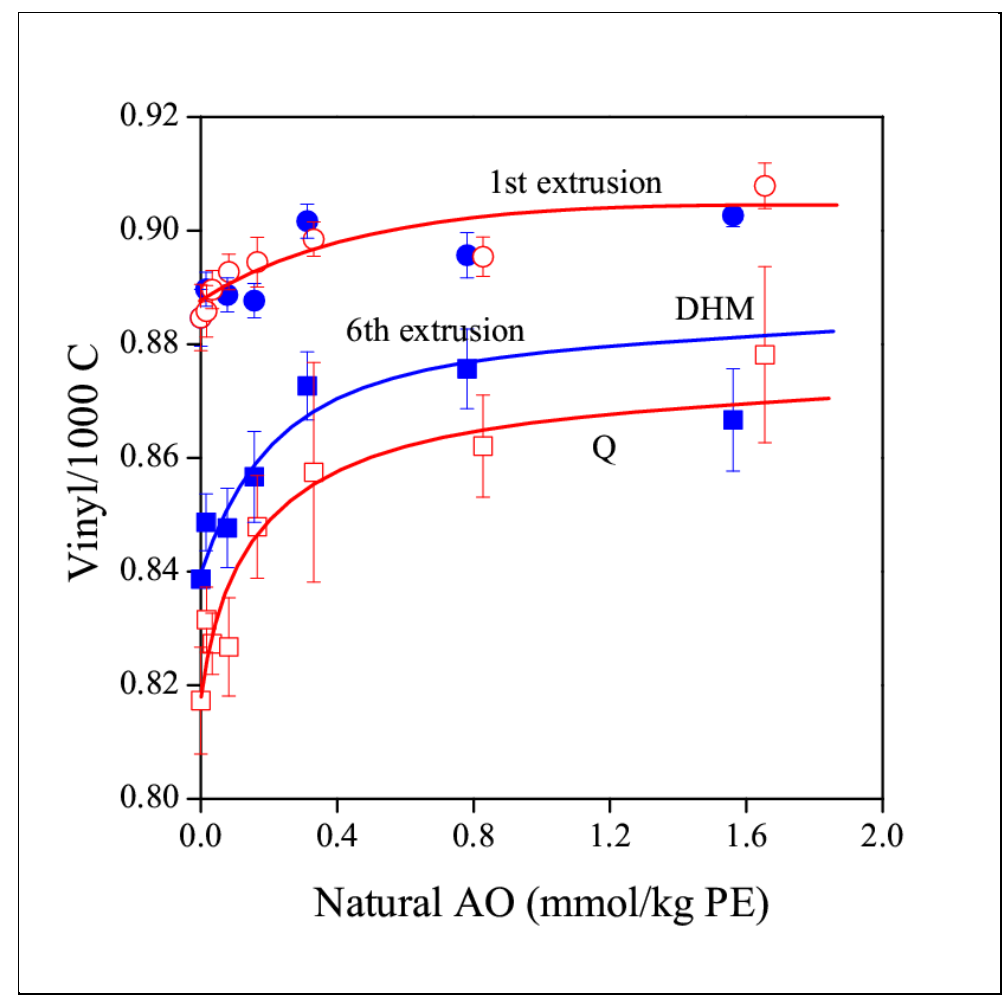

Fig. 3 Changes in the vinyl group content of polyethylene as a function of antioxidant content and processing history. Symbols are the same as in Fig. 2.

Changes in viscosity and processability are attributed to the formation of LCBs going through the chain-end vinyl groups of the polymer [32,33]. The effect of additive content and processing history (No. of extrusions) on the vinyl group content of the polymer is presented in Fig. 3. The number of vinyl groups increase with increasing additive concentration indicating that less vinyl groups enter into chain extension reactions during processing. The effect of the two additives is similar in the first extrusion, but DHM is more efficient than quercetin at larger number of extrusions. The correlations presented in Fig. 3 clearly prove that changes in MFR are caused by the reactions of the vinyl groups indeed. Several studies proved that the role of the secondary stabilizer is essential in the protection of the polymer 
against degradation especially in the first processing step [34]. The amount of residual secondary stabilizer is plotted against the number of extrusions in Fig. 4 at two additive contents. All the differences observed earlier in Figs. 1-3 can be detected also here. PEPQ content decreases drastically with increasing number of extrusions at small antioxidant content, while much slower at $500 \mathrm{ppm}$ stabilizer concentration. The larger efficiency of DHM can be clearly seen in the figure. Obviously all the processes taking place during the extrusion of polyethylene are related to each other. The natural antioxidant and the phosphorous secondary stabilizer prevents the reaction of the vinyl groups in a synergistic action, while the natural antioxidant protects PEPQ and decreases its rate of consumption. We may conclude that both natural antioxidants used in this study are efficient processing stabilizers and that the effect of DHM surpasses that of quercetin in melt stabilization.

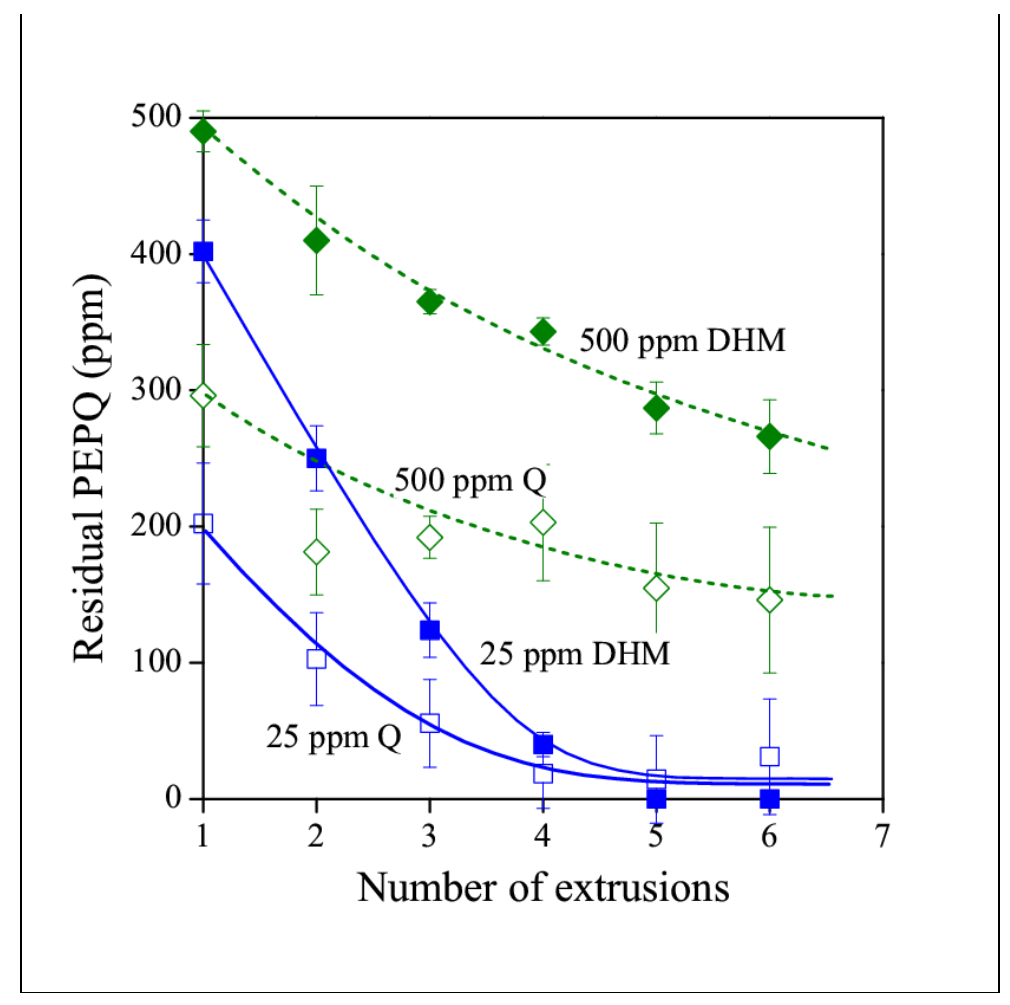

Fig. 4 Effect of the number of extrusions and antioxidant content on the residual amount of PEPQ in polyethylene processed in multiple extrusions. Symbols: $(\square) 25,(\diamond)$ 


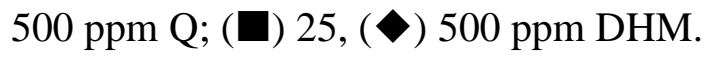

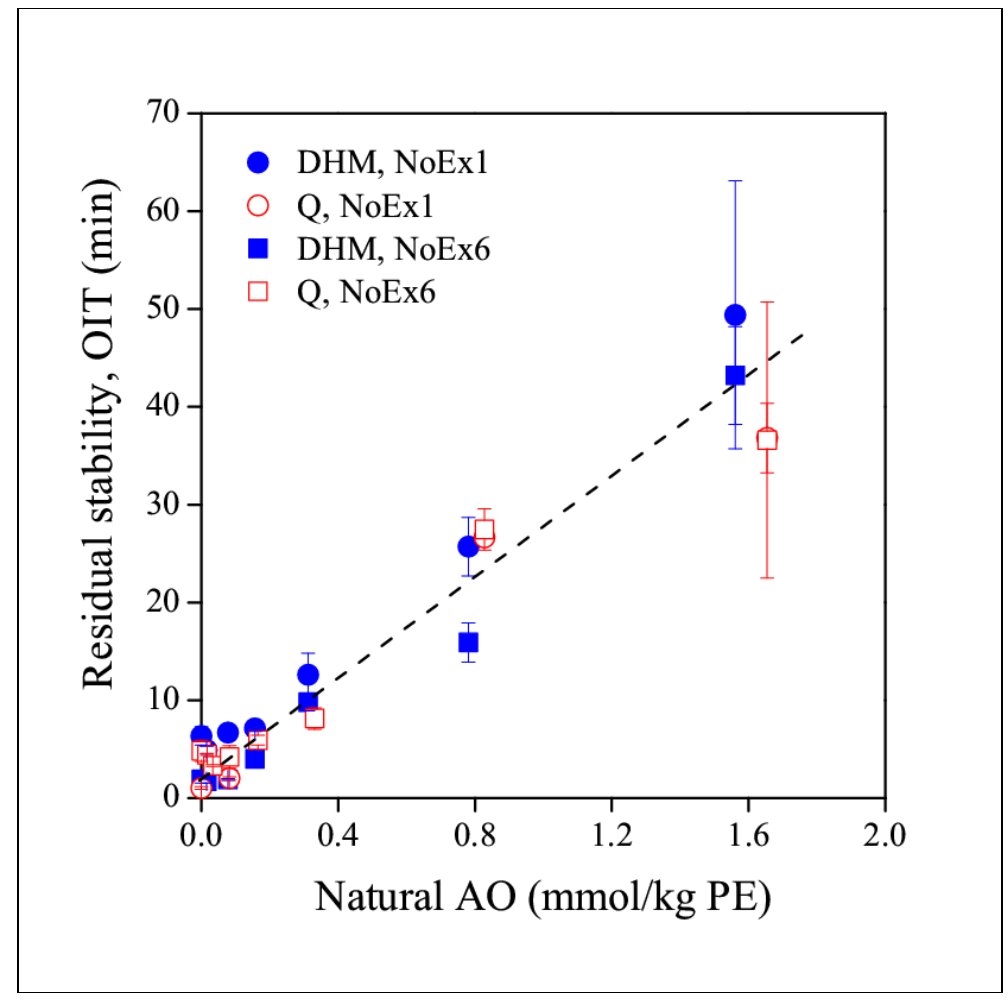

Fig. 5 Unique correlation between the amount of the natural antioxidant used and the residual stability (OIT) of polyethylene. Symbols are the same as in Fig. 2.

\subsection{Residual stability}

Processing stability is important for most products, but long term stability can be also crucial in certain applications like in gas or water pipes. Moreover, residual stability may offer further information about the mechanism of stabilization and the effect of the chemical structure of the stabilizer on efficiency. The residual stability of PE is plotted against the amount of stabilizer used in Fig. 5. Concentration is expressed in mmol antioxidant/kg PE units, which disregards the different number of phenolic $-\mathrm{OH}$ groups in the molecule. The correlation is linear and the effect of the two antioxidants is similar. The linearity is not very surprising, since several authors have proved that OIT is linearly proportional to the amount of phenolic antioxidant [35-37]. Obviously the slope of the straight 
line depends on the structure of the stabilizer and on the additive package, i.e. on the type and amount of secondary stabilizer and other components used [35]. However, only limited information is available on the effect of these latter factors on residual stability.

The unique correlation is much more surprising. Based on the larger number of phenolic hydroxyls in DHM, as well as on the results presented in the previous section, one would expect larger stability in polymers containing this additive [24,25]. According to these results not all phenolic $-\mathrm{OH}$ groups react during the measurement of OIT and the stabilization effect does not depend on the number of functional groups, but only on the amount of stabilizer present. This result raises the question of reaction mechanism and the activity of the reaction products formed in the first stabilization reaction.

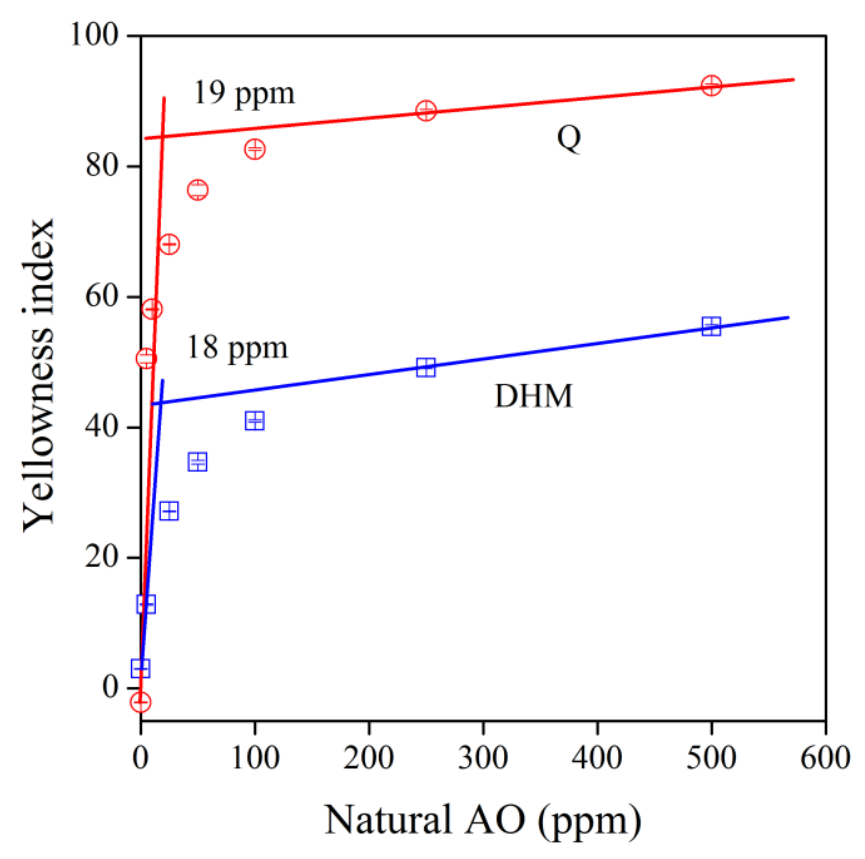

Fig. 6 Determination of the solubility of the natural antioxidants studied from the concentration dependence of color after the $1^{\text {st }}$ extrusion. Symbols: $(\bigcirc) \mathrm{Q},(\square)$ DHM. 


\subsection{Solubility}

The solubility of stabilizers is important for their effect. Larger solubility results in better homogeneity and efficiency [38]. Quercetin was shown to have very limited solubility in PE indicated by the composition dependence of color and by the fact that quercetin crystals were observed in the polymer at larger additive contents [23]. The yellowness index of the polymer is plotted against antioxidant concentration in Fig. 6. The measurement was done after the first extrusion step. The discoloration effect of quercetin is very strong, yellowness index reaches more than 90 at large additive content. Rather surprisingly DHM originally being a white powder also discolors the polymer quite strongly, yellowness indices in the range of 50 were measured. Apparently, the reaction products of the stabilizer are not colorless, they discolor the polymer significantly.

The composition dependence of color was used earlier for the determination of the solubility of quercetin in polyethylene [23]. The same approach was used in this study and the result is shown in Fig. 6. The basic idea behind the determination of solubility is that dissolved stabilizer molecules have a much stronger effect on color than the additive being present as a separate phase, in the form of crystals. This concept is definitely valid for quercetin, but more difficult to accept for DHM, since discoloration seems to be caused by the reaction products of the additive. Comparison is further complicated by the small number of points in the steeply increasing leg of the correlation and the different levels of color caused by the two additives. Nevertheless, we can state that the correlations as well as the solubility levels are similar, the latter being very small, in the range of $15-20 \mathrm{ppm}$. This similarity is not surprising since the molecular structure of the two additives is similar. Fortunately, this limited solubility does not influence the efficiency of the two compounds in stabilization. 


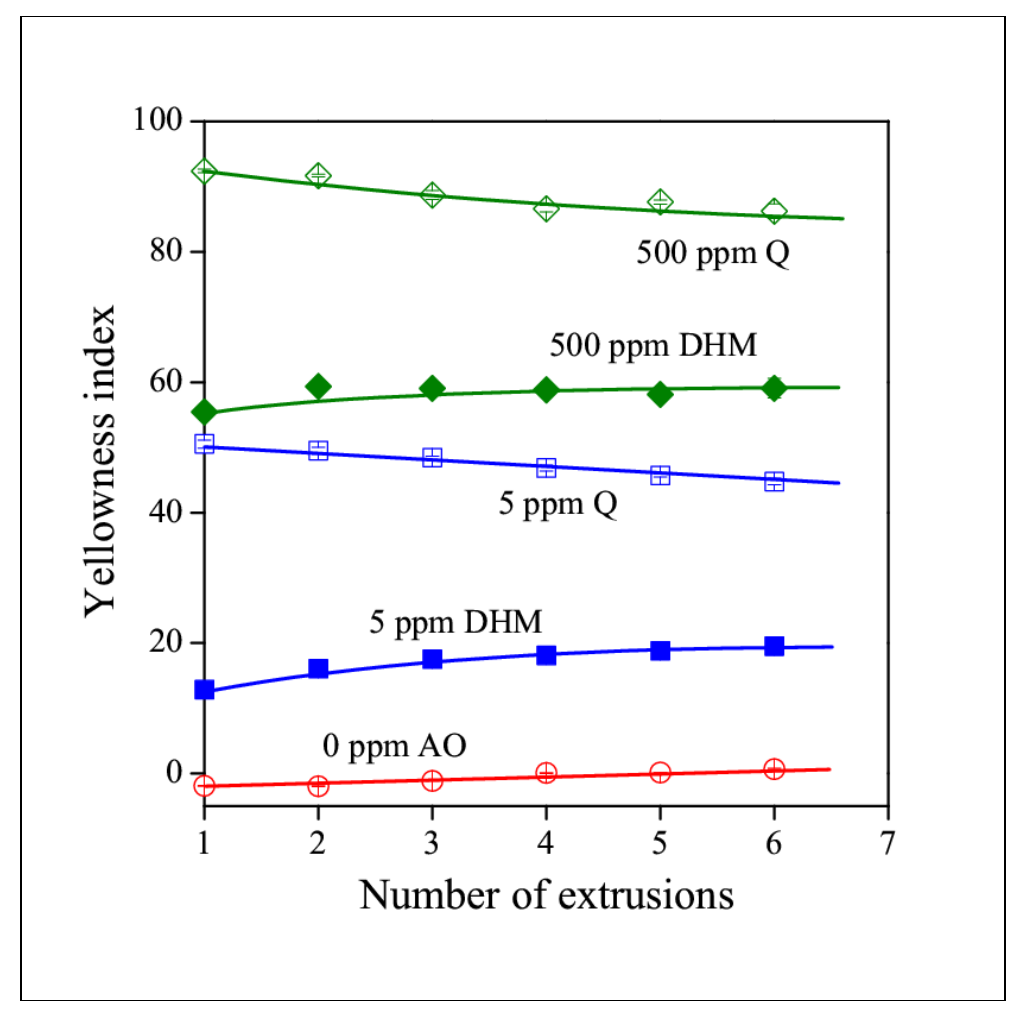

Fig. 7 Effect of additive content and processing history (No. of extrusions) on the yellowness index of polyethylene. Symbols: $(\bigcirc)$ no primary antioxidant, $(\square) 5,(\diamond) 500$ ppm Q; (ם) 5, (•) 500 ppm DHM.

\subsection{Color}

The color of the product is very important in some applications, while much less of an issue in others. In black products the possible discoloration effect of the additive does not matter, but colorless compounds are often much more advantageous. The yellowness index of polyethylene is plotted against the number of extrusions in Fig. 7 for compounds containing the two additives in selected amounts. The very strong coloring effect of quercetin is seen already at $5 \mathrm{ppm}$ additive content and discoloration is extremely intense at 500 ppm. As mentioned above DHM colors the polymer less. Interestingly the measured values slightly decrease during consecutive processing steps in the case of quercetin, and increase 
for dihydromyricetin. The consumption of the dissolved yellow stabilizer results in the decrease in the first case, while the formation of colored reaction products leads to the deepening of color in the second. However, yellowness index does not reflect the hue of the color well, especially if it differs from yellow. The Optical $\mathrm{L}^{*}$ parameter gives an idea about the deviation from white; the larger the value is, the closest is the color to white. The $\mathrm{L}^{*}$ parameter decreases slightly with increasing quercetin content and does not change much with increasing number of extrusions; it takes values between 76 and 63. On the other hand, the $\mathrm{L}^{*}$ parameter decreases both with additive content and the number of extrusions for DHM and changes between 76 and 37 in the studied range. These relationships are demonstrated much better by Figs. 8a and $\mathbf{b}$ than by the optical L* parameter. In Fig. 8a the effect of additive content on color is shown after the first extrusion, while the influence of processing history can be seen in Fig. $\mathbf{8 b}$ at 500 ppm additive content. It is clear from the figure that quercetin colors the polymer to yellowish red, while DHM from light ochre to dark brown. Obviously, we could not solve the problem of discoloration by the selection of the new natural antioxidant, dihydromyricetin. 


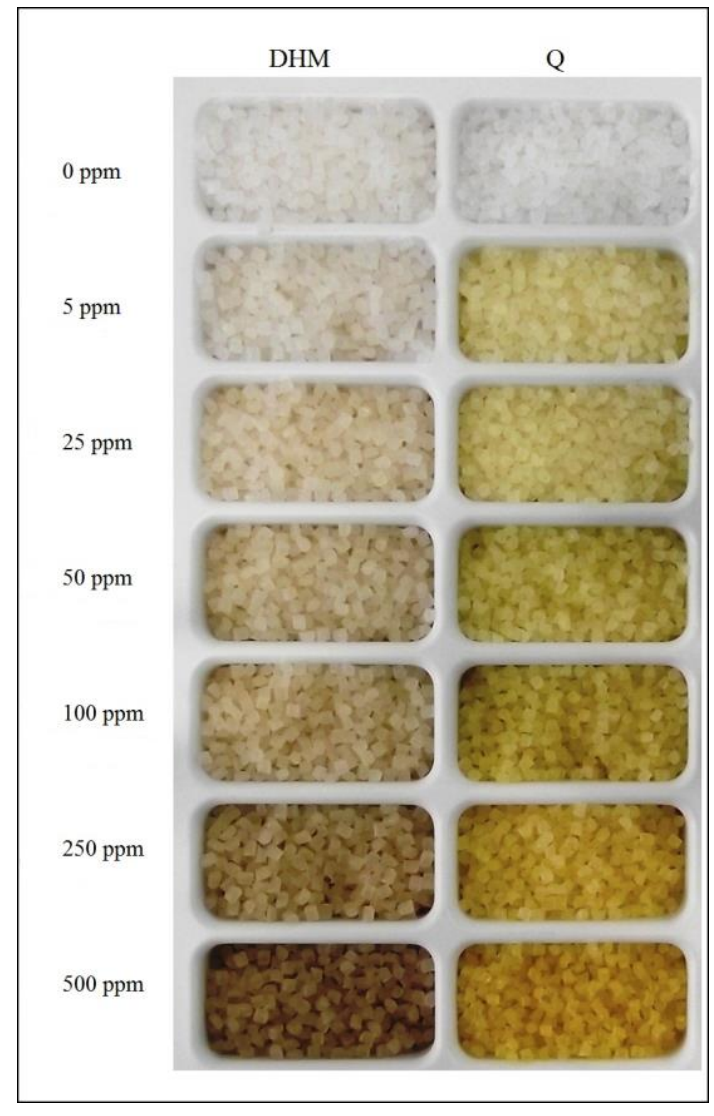

a)

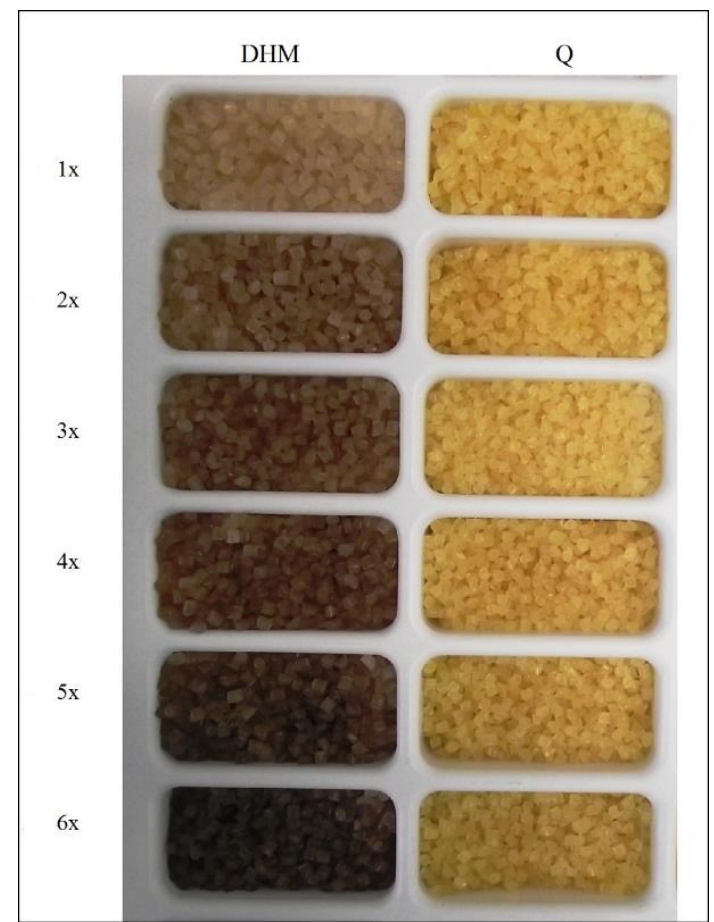

b)

Fig. 8 Changing color of polyethylene in the presence of the two natural antioxidants studied; a) effect of additive content, $1^{\text {st }}$ extrusion, b) effect of the number of extrusions, $500 \mathrm{ppm}$.

\subsection{Discussion}

The result presented above prove that both natural antioxidants are efficient melt stabilizers for polyethylene. However, some of the results, like the similar effect on residual stability, or the discoloration of the polymer in the presence of DHM were somewhat unexpected. The reactivity and stabilization effect of phenolic antioxidants depend on their chemical structure, on the number of hydroxyl groups and their position. Four mechanisms have been proposed in the literature for the stabilization reactions of phenolic antioxidants: single electron transfer (SET) [39-40], sequential proton loss electron transfer (SPLET) [41- 
42], radical adduct formation (RAF) [43] and hydrogen atom transfer (HAT) [44-45]. In polyethylene the last one is the most probable and accepted mechanism of stabilization. The rate of hydrogen transfer depends on the dissociation enthalpy of the hydrogen atom from the phenolic hydroxyl and this is smaller for the hydrogens located on the $\mathrm{OH}$ groups in the B ring of DHM than in quercetin [30-31]. According to the OIT results shown in Fig. 5 $\mathrm{DHM}$ is not more efficient than quercetin in spite of the larger number of $-\mathrm{OH}$ groups in the molecule. This indicates that after the first reaction, in spite of the reactivity of the products formed, both molecules become much less active than the original compound. This explains the similarity of their effect, but not the differences in efficiency in protecting the polymer during processing.

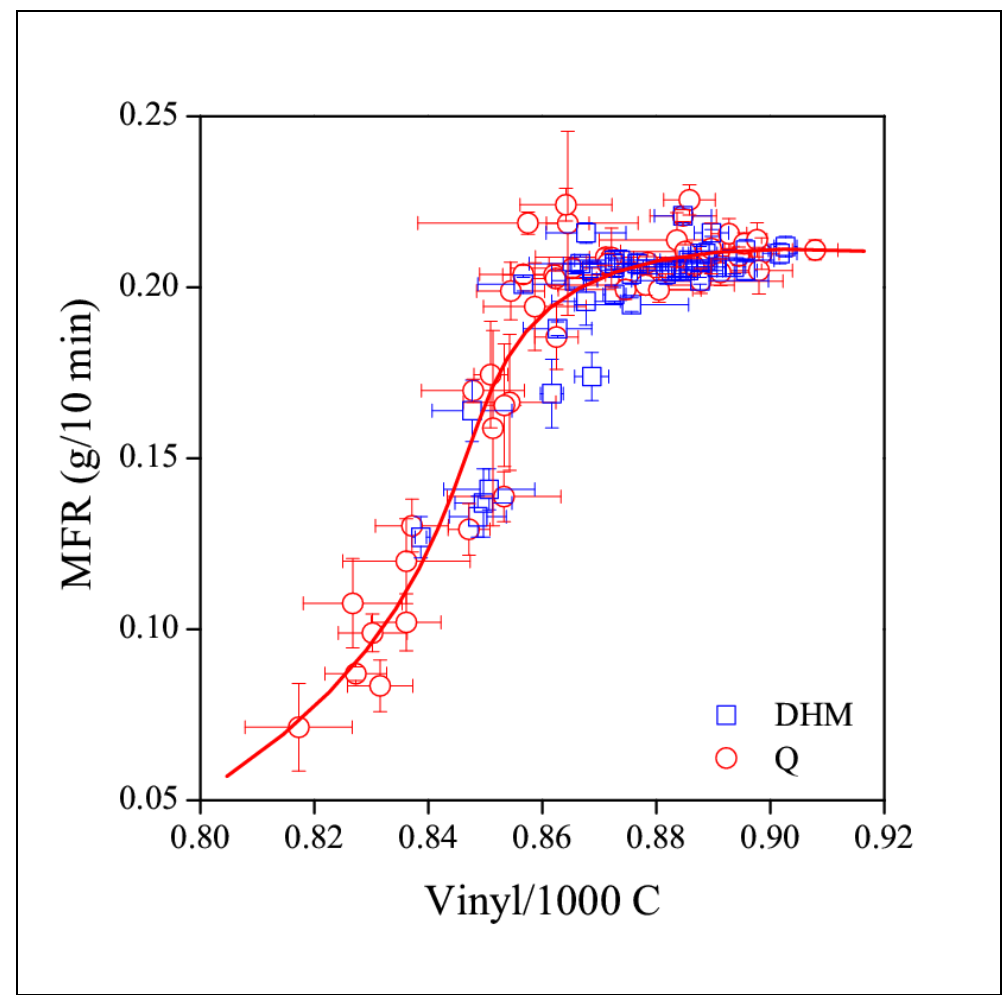

Fig. 9 Correlation between the vinyl content of polyethylene and its melt flow rate. Symbols: (○) Q, ( $\square)$ DHM. 
As discussed earlier long chain branches form during processing through the reaction of the vinyl groups located at one end of the polyethylene chains. The combined, synergetic effect of the primary and secondary antioxidant hinders this reaction, but the interaction of the two stabilizers decreases also their consumption rate. The correlation between the vinyl content of the polymer and MFR is presented in Fig 9. It is clear that viscosity is constant above a certain vinyl content and increases drastically below that (approximately 0.86 vinyl/1000 C). The larger efficiency of DHM is shown by the fact that the points (squares) for the polymer containing this additive are located on the upper right part of the correlation, while many of those belonging to quercetin (circles) appear in the lower left range. The crucial role of the phosphorous antioxidant is demonstrated well by the fact that below a certain PEPQ content (approximately 100 ppm) MFR starts to decrease drastically to very small values. The interaction of the two types of stabilizers (primary, secondary) is important and different for the two natural antioxidants leading to the larger efficiency of DHM. The exact nature of this interaction and the mechanism of stabilization need further study and considerations.
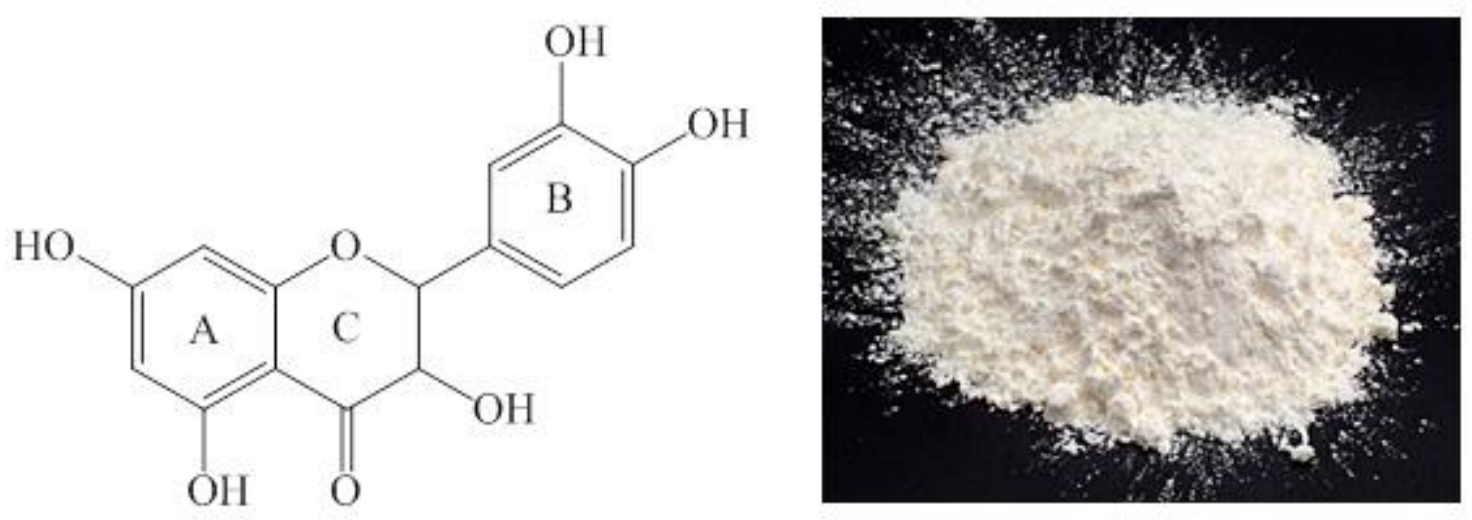

Fig. 10 Chemical structure and appearance of dihydroquercetin (taxifolin) having no double bond in its ring $\mathrm{C}$. 
The disappointing color change also requires explanation. The strong yellow color of quercetin results from the conjugation of the double bond in the $\mathrm{C}$ with the electrons in the B ring. Dihydroquercetin (or taxifolin) is a white powder similarly to DHM (Fig. 10). As a consequence, the brownish color must form during the processing of the polymer containing the antioxidants. Various quinoidal compounds may form as a result of stabilization reactions which depend on the molecular structure of the antioxidant. Assuming that hydrogen transfer occurs from the B ring, the reaction of quercetin results in two compounds, while that of DHM in one. The reaction leading to these compounds and their structures are presented in Fig. 11. Obviously all three are conjugated systems absorbing light in the visible range.

a)

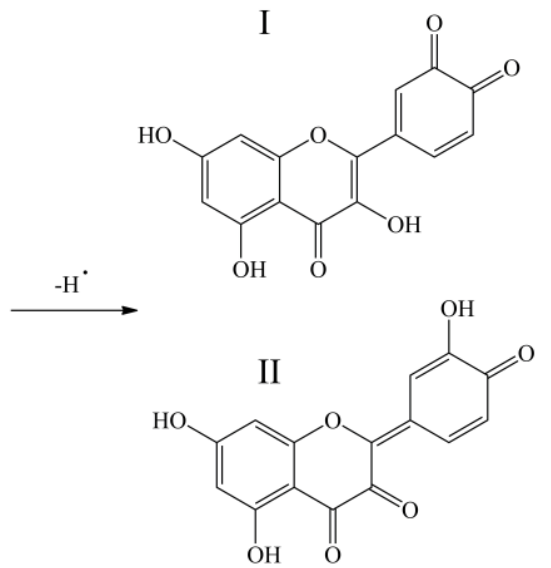

b)<smiles>O=C1c2c(O)cc(O)cc2OC(c2cc(O)c(O)c(O)c2)C1O</smiles><smiles>CC(C)C</smiles><smiles>CC(C)C</smiles>

Fig. 11 Formation of quinoidal compounds in stabilization reactions; a) quercetin, b) dihydromyricetin. 


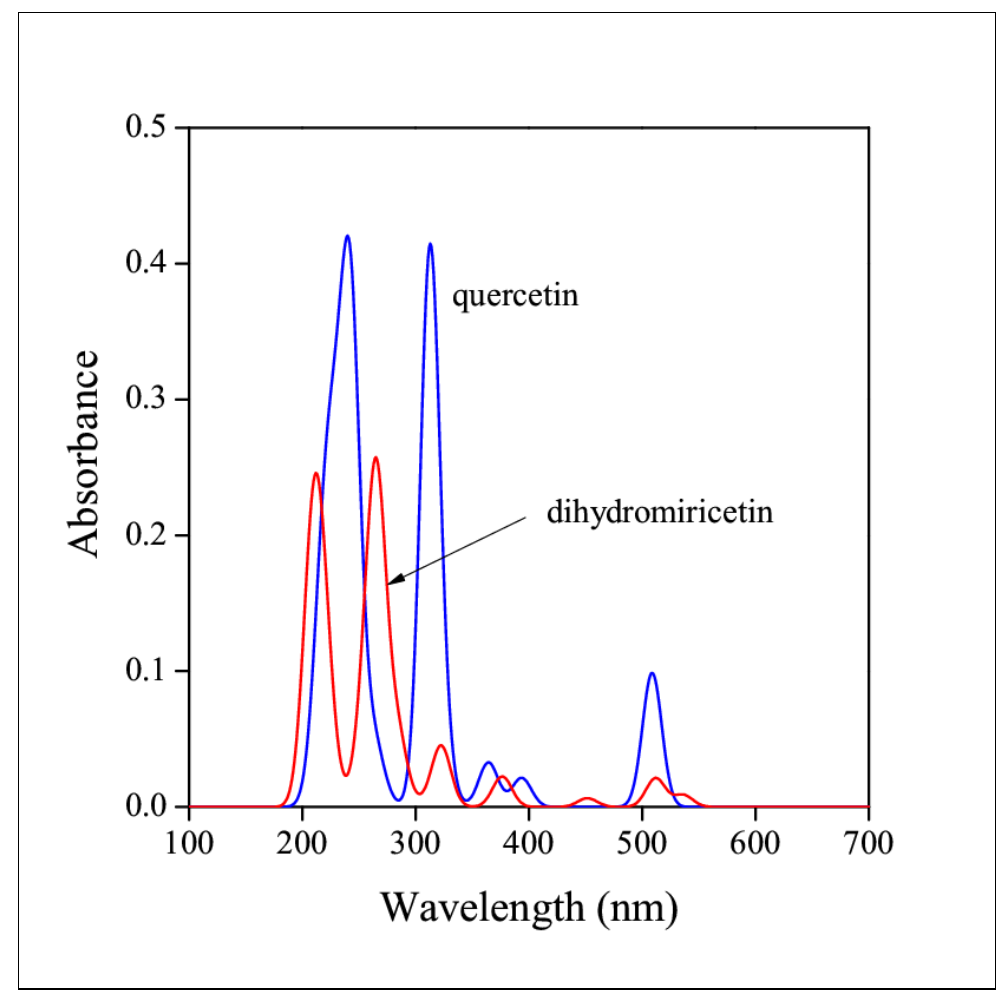

Fig. 12 Predicted UV-VIS spectra of the quinoidal compounds forming from the natural antioxidants during stabilization; a) quercetin I, b) dihydromyricetin III.

An attempt was made to estimate the color of these compounds by molecular modeling. The spectra resulting from the calculations are shown in Fig. 12 for two compounds, compound I formed from quercetin and compound III derived from DHM. Absorption bands appear at 240, 314, 364, 394 and $509 \mathrm{~nm}$ in the spectrum of the first, but we are interested only in the visible region. At 394 and $509 \mathrm{~nm}$ the violet and green components of visible light are absorbed leading to a mixture of red and yellow colors. The absorption of compound II also results in yellow-orange colors confirmed by Figs. 8a and b. Similarly, compound III absorbs at 378, 452, 511 and $537 \mathrm{~nm}$ corresponding to lilac, blue, and green colors. Brown is a mixed color resulting from the absorption of the blue components of light, thus it is highly probable that this absorption leads to the ochre-brownish color of the polymer 
processed in the presence of dihydromyricetin (see Fig. 8). However, in spite of this discoloration the natural antioxidants studied in this work are efficient stabilizers of PE and can be used for certain products.

\section{CONCLUSIONS}

Experiments carried out to determine the stabilization activity of two flavonoid type natural antioxidants in polyethylene proved that both stabilize PE very efficiently. At small concentrations dihydromyricetin proved to be more efficient melt stabilizer than quercetin, less vinyl groups were consumed during processing, less long chain branches formed and thus MFR was larger in its presents than with the same amount of quercetin. DHM protected the secondary antioxidant better than quercetin, less PEPQ was consumed in its presence during processing. In spite of its better efficiency in melt stabilization, polymers containing DHM had the same residual stability as those prepared with quercetin. Accordingly, the larger efficiency does not result from the larger number of active phenolic hydroxyls in this molecule, but from interaction with the phosphorous secondary stabilizer that is stronger or at least different for DHM than for quercetin. Although DHM is a white powder, it gave the polymer brownish color which became stronger with increasing number of extrusions and additive content. In spite of this slight disadvantage both natural antioxidants can be efficiently used for the stabilization of polymers in applications in which color is of secondary importance.

\section{ACKNOWLEDGEMENTS}

The National Research Fund of Hungary (OTKA K 120039) is greatly acknowledged for the financial support of the research. The computing time granted on the Hungar- 
ian HPC Infrastructure at the NIIF Institute, Hungary, is also highly appreciated. The research work has been accomplished in the framework of the BME $\mathrm{R}+\mathrm{D}+\mathrm{I}$ project, supported by the grant TÁMOP 4.2.1/B-09/1/KMR-2010-0002.

\section{REFERENCES}

[1] Brocca D, Arvin E, Mosbaek H. Identification of organic compounds migrating from polyethylene pipelines into drinking water. Water Res 2002;36(15):3675-3680.

[2] Pokorny J. Natural antioxidants for food use. Trends Food Sci Technol 1991;2:223227.

[3] Falowo AB, Fayemi PO, Muchenje V. Natural antioxidants against lipid-protein oxidative deterioration in meat and meat products: A review. Food Res Int 2014;64:171-181.

[4] Embuscado ME. 11 - Herbs and spices as antioxidants for food preservation. Shahidi F. Handbook of Antioxidants for Food Preservation. Woodhead Publishing Series in Food Science, Technology and Nutrition 2015;251-283.

[5] Al-Malaika S, Ashley H, Issenhuth S. The antioxidant role of $\alpha$-tocopherol in polymers. I. The nature of transformation products of $\alpha$-tocopherol formed during melt processing of LDPE. J Polym Sci A-1 1994;32:3099-3113.

[6] Al-Malaika S, Goodwin C, Issenhuth S, Burdick D. The antioxidant role of alphatocopherol in polymers II. Melt stabilising effect in polypropylene. Polym Degrad Stab 1999;64(1):145-156.

[7] Al-Malaika S, Issenhuth S. The antioxidant role of alpha-tocopherol in polymers III. Nature of transformation products during polyolefins extrusion. Polym Degrad Stab 1999;65(1):143-151. 
[8] Al-Malaika S, Issenhuth S, Burdick D. The antioxidant role of vitamin E in polymers V. Separation of stereoisomers and characterisation of other oxidation products of DL-alpha-tocopherol formed in polyolefins during melt processing. Polym Degrad Stab 2001;73(3):491-503.

[9] Alexy P, Kosikova B, Podstranska G. The effect of blending lignin with polyethylene and polypropylene on physical properties. Polymer 2000;41(13):49014908.

[10] Pouteau C, Dole P, Cathala B, Averous L, Boquillon N. Antioxidant properties of lignin in polypropylene. Polym Degrad Stab 2003;81(1):9-18.

[11] Gregorová A, Kosikova B, Moravcik R. Stabilization effect of lignin in natural rubber. Polym Degrad Stab 2006;91(2):229-233.

[12] Pereira de Abreu DA, Paseiro Losada P, Maroto J, Cruz JM. Natural antioxidant active packaging film and its effect on lipid damage in frozen blue shark (Prionace glauca). Innov Food Sci Emerg 2011;12(1):50-55.

[13] Pereira de Abreu DA, Maroto J, Villalba Rodriguez K, Cruz JM. Antioxidants from barley husks impregnated in films of low-density polyethylene and their effect over lipid deterioration of frozen cod (Gadus morhua). J Sci Food Agr 2012;92(2):427432.

[14] Cerruti P, Malinconico M, Rychly J, Matisova-Rychla L, Carfagna C. Effect of natural antioxidants on the stability of polypropylene films. Polym Degrad Stab 2009;94(11):2095-2100.

[15] Ambrogi V, Cerruti P, Carfagna C, Malinconico M, Marturano V, Perrotti M, Persico P. Natural antioxidants for polypropylene stabilization. Polym Degrad Stab 2011;96(12):2152-2158. 
[16] Tátraaljai D, Kirschweng B, Kovács J, Földes E, Pukánszky B. Processing stabilisation of PE with a natural antioxidant, curcumin. Eur Polym J 2013;49(6):1196-1203.

[17] Koontz JL, Marcy JE, O'Keefe SF, Duncan SE, Long TE, Moffitt RD. Polymer processing and characterization of LLDPE films loaded with alpha-tocopherol, quercetin, and their cyclodextrin inclusion complexes. J Appl Polym Sci 2010;117(4):2299-2309.

[18] Samper MD, Fages E, Fenollar O, Boronat T, Balart R. The potential of flavonoids as natural antioxidants and UV light stabilizers for polypropylene. J Appl Polym Sci 2013;129(4):1707-1716.

[19] Lopez-de-Dicastillo C, Gomez-Estaca J, Catala R, Gavara R, Hernandez-Munoz P. Active antioxidant packaging films: Development and effect on lipid stability of brined sardines. Food Chem 2012;131(4):1376-1384.

[20] Lopez-de-Dicastillo C, Alonso JM, Catala R, Gavara R, Hernandez-Munoz P. Improving the antioxidant protection of packaged food by incorporating natural flavonoids into ethylene-vinyl alcohol copolymer (EVOH) films. J Agr Food Chem 2010;58(20):10958-10964.

[21] Chen X, Lee DS, Zhu XT, Yam KL. Release kinetics of tocopherol and quercetin from binary antioxidant controlled-release packaging films. J Agr Food Chem 2012;60(13):3492-3497.

[22] Koontz JL, Moffitt RD, Marcy JE, O'Keefe SF, Duncan SE, Long TE. Controlled release of $\alpha$-tocopherol, quercetin, and their cyclodextrin inclusion complexes from linear low-density polyethylene (LLDPE) films into a coconut oil model food system. Food Addit Contam A 2010;27(11):1598-1607. 
[23] Tátraaljai D, Földes E, Pukánszky B. Efficient melt stabilization of polyethylene with quercetin, a flavonoid type natural antioxidant. Polym Degrad Stab 2014;102(1):41-48.

[24] Xin M, Ma Y, Xu K, Chen M. Dihydromyricetin: An effective non-hindered phenol antioxidant for linear low-density polyethylene stabilisation. J Therm Anal Calorim 2013;114(3):1167-1175.

[25] Xin M, Ma Y, Lin W, Xu K, Chen M. Use of dihydromyricetin as antioxidant for polypropylene stabilization. J Therm Anal Calorim. 2015;120(3):1741-1747.

[26] Perdew JP, Ernzerhof M, Burke K. Rationale for mixing exact exchange with density functional approximations. J Chem Phys 1996;105(22):9982-9985.

[27] Frisch MJ, Pople JA, Binkley JS. Self-consistent molecular orbital methods 25. Supplementary functions for Gaussian basis sets. J Chem Phys 1984;80(7):32653269.

[28] Halgren TA. Merck molecular force field. I. Basis, form, scope, parameterization, and performance of MMFF94, J Comput Chem 1996;17(5-6):490-519.

[29] Gaussian 09, Revision E.01, Frisch, MJ, Trucks GW, Schlegel HB, Scuseria GE, Robb MA, Cheeseman JR, Scalmani G, Barone V, Mennucci B, Petersson GA, Nakatsuji H, Caricato M, Li X, Hratchian HP, Izmaylov AF, Bloino J, Zheng G, Sonnenberg JL, Hada M, Ehara M, Toyota K, Fukuda R, Hasegawa J, Ishida M, Nakajima T, Honda Y, Kitao O, Nakai H, Vreven T, Montgomery JA Jr, Peralta JE, Ogliaro F, Bearpark M, Heyd JJ, Brothers E, Kudin KN, Staroverov VN, Kobayashi R, Normand J, Raghavachari K, Rendell A, Burant JC, Iyengar SS, Tomasi J, Cossi M, Rega N, Millam JM, Klene M, Knox JE, Cross JB, Bakken V, Adamo C, Jaramillo J, Gomperts R, Stratmann RE, Yazyev O, Austin AJ, Cammi R, Pomelli C, Ochterski JW, Martin RL, Morokuma K, Zakrzewski VG, Voth GA, Salvador P, 
Dannenberg JJ, Dapprich S, Daniels AD, Farkas Ö, Foresman JB, Ortiz JV, Cioslowski J, Fox DJ. Gaussian Inc., Wallingford CT, 2009.

[30] Zhang HY. Theoretical methods used in elucidating activity differences of phenolic antioxidants. J Am Oil Chem Soc 1999;76:745-748.

[31] Thavasi V, Leong LP, Bettens RPA. Investigation of the influence of hydroxy groups on the radical scavenging ability of polyphenols. J Phys Chem A 2006;110:4918-4923.

[32] Chirinos-Padrón AJ, Hernández PH, Chávez E, Allen NS, Vasiliou C, DePoortere M. Influences of unsaturation and metal impurities on the oxidative degradation of high density polyethylene. Eur Polym J 1987;23:935-40.

[33] Epacher E, Fekete E, Gahleitner M, Pukánszky B. Chemical reactions during the processing of stabilized PE: 2. Structure/property correlations. Polym Degrad Stab 1999;63(3):499-507.

[34] Kriston I, Orbán-Mester Á, Nagy G, Staniek P, Földes E, Pukánszky B. Melt stabilisation of Phillips type polyethylene, Part I: The role of phenolic and phosphorous antioxidants. Polym Degrad Stab 2009;94(4):719-729.

[35] Moss S, Zweifel H. Degradation and stabilization of high density polyethylene during multiple extrusions. Polym Degrad Stab 1989;25:217-245.

[36] Klemchuk PP, Horng PL. Transformation products of hindered phenolic antioxidants and colour developments in polyolefins. Polym Degrad Stab 1991;34:333-346.

[37] Breese KD, Lamethe JF, DeArmitt C. Improving synthetic hindered phenol antioxidants: learning from vitamin E. Polym Degrad Stab 2000;70:89-96

[38] Frank HP, Frenzel R. Solubility of additives in polypropylene. Eur Polym J 1980;16(7):647-649. 
[39] Jovanovic SV, Steenken S, Tosic M, Marjanovic B, Simic MG. Flavonoids as Antioxidants. J Am Chem Soc 1994;116:4846-4851.

[40] Jovanovic SV, Steenken S, Hara Y, Simic MG. Reduction potentials of flavonoid and model phenoxyl radicals. Which ring in flavonoids is responsible for antioxidant activity? J Chem Soc Perkin Trans 2 1996;2:2497-2504.

[41] Litwinienko G, Ingold KU. Abnormal solvent effects on hydrogen atom abstraction. 1. The reactions of phenols with 2,2-diphenyl-1-picrylhydrazyl (dpph*) in alcohols. J Org Chem 2003;68(9):3433-3438.

[42] Zhang HY, Ji HF. How vitamin E scavenges DPPH radicals in polar protic media. New J Chem 2006;30:503-504.

[43] Anouar E, Kosinova P, Kozlowski D, Mokrini R, Duroux JL, Trouillas P. New aspects of the antioxidant properties of phenolic acids: a combined theoretical and experimental approach. Phys Chem Chem Phys 2009;11:7659-7668.

[44] Burton GW, Doba T, Gabe EJ, Hughes L, Lee FL, Prasad L, Ingold KU. Autooxidation of biological molecules. 4. Maximizing the antioxidant activity of phenols. J Am Chem Soc 1985;107:7053-7065.

[45] de Heer MI, Mulder P, Korth HG, Ingold KU, Lusztyk J. Hydrogen atom abstraction kinetics from intramolecularly hydrogen bonded ubiquinol-0 and other (poly)methoxy phenols. J Am Chem Soc 2000;122:2355-2360. 